\title{
Development of Medical Radiation Shield Using Density-Enhanced Recycled Oyster Shells
}

Seon-Chil Kim ( $\nabla$ rontgen7@gmail.com )

Keimyung University School of Medicine

\section{Research Article}

Keywords: Oyster shell, radiation-based techniques, polymer material

Posted Date: June 17th, 2021

DOI: https://doi.org/10.21203/rs.3.rs-620534/v1

License: (c) (i) This work is licensed under a Creative Commons Attribution 4.0 International License. Read Full License 


\title{
Development of medical radiation shield using density-enhanced recycled oyster shells
}

\section{Seon-Chil Kim ${ }^{*}$}

\author{
*Professor, Department of Biomedical Engineering, Keimyung University School of Medicine, Daegu, Korea \\ rontgen7@gmail.com
}

\begin{abstract}
As radiation-based techniques become an increasingly important tool for medical diagnostics, medical professionals face an increasing risk from the long-term effects of scattered radiation exposure. Although existing radiation-shielding products used in medicine are traditionally lead-based, recently, attention has turned to the development of more eco-friendly materials such as tungsten, bismuth, and barium sulfate. To date, however, the proposed alternative materials have struggled to compete with lead in terms of shielding performance and economic feasibility. This study explores the potential of radiation shielding materials based on the shells of bivalve mollusks such as oysters that are discarded from aquaculture, thereby preventing them from going to landfill. In addition, a firing process for enhancing the shielding performance of the original material is proposed. Experiments showed that shielding sheets comprising 0.3-mm-thick layers of oyster shell achieve a shielding efficiency of $37.32 \%$ for the low-energy X-rays typically encountered in medical institutions. In addition, the shielding performance was improved by increasing the density of the powdered oyster shell via plastic working at 1,200 ${ }^{\circ} \mathrm{C}$. This raises the possibility of developing multi-material radiation shields and highlights a new potential avenue for recycling aquacultural waste.
\end{abstract}

\section{Introduction}

Scattered radiation poses a long-term exposure risk to medical professionals working in hospital radiography units ${ }^{1,2,3}$. To mitigate this risk, medical personnel wear protective aprons when operating radiation-emitting equipment. These aprons are usually manufactured based on lead sheets ${ }^{4,5,6,7}$, and an apron with a lead equivalent of $0.25 \mathrm{mmPb}$ weighs $3.25 \mathrm{~kg}$, and an apron with a lead equivalent of $0.5 \mathrm{mmPb}$ weighs about $4.95 \mathrm{~kg}^{8,9}$. Therefore, these weights limit their activity. To solve this problem, extensive research is being devoted to the development of new radiation-shielding materials, with lighter, more ecofriendly materials including tungsten, bismuth, barium, boron, and tin among the alternatives proposed ${ }^{10,11,12,13,14}$. These lead substitutes are free from the risks associated with heavy metals; however, to be used for radiation-shielding sheets, they must be compatible with polymeric materials ${ }^{15,16}$. In addition, the economic feasibility of new shielding materials is an important factor regarding their commercial prospects. Therefore, the challenge facing researchers is the delivery of shielding materials that are both economically feasible and satisfy the weight and human-safety requirements.

This study explores the viability of developing radiation-shielding materials by processing oyster shells that would otherwise be discarded as general waste. Various shellfish, such as oysters, clams, and mussels, live in coastal waters and can be collected for processing. Such shellfish are characterized by a large volume of shell compared to the housed meat, and the large amount of shells discarded from aquaculture are attracting attention as a major source of waste and a cause of environmental pollution along coastlines and in landfills ${ }^{17,18}$. Currently, the shell recycling industry is very limited, and there are cases where shells are typically recycled as soil fertilizer. However, this industry does not have significant economic value $^{19}$. The main component of the shell is calcium (atomic number 20), which reacts easily with oxygen and water. In nature ( such as in coastal areas), it exists in the form of compounds such as calcium carbonate $\left(\mathrm{CaCO}_{3}\right)$. Lead has an atomic number of 82 and a density of $11.34 \mathrm{~g} / \mathrm{cm}^{3}$. The density of calcium carbonate is $1.55 \mathrm{~g} / \mathrm{cm}^{3}$, which has a lower radiation shielding condition than lead.

Oyster shell is easy to process because it contains a large amount of salt and has a porous structure. In addition, it shows an excellent affinity for mixing with other materials, which has led to it being studied as an aggregate for construction materials, while it has been mixed with concrete during research on gamma ray shielding $22,23,24$. Therefore, the first objective of this study is to test the hypothesis that oyster shell is an ideal candidate for mixing with polymer materials because of its high compatibility and radiation-shielding properties. To this end, the characteristics of powdered oyster shell were analyzed by conducting plastic working at different temperatures, with the particle distribution evaluated with regard to the cross-sectional structure of a polymer-based shielding sheet. Furthermore, the effect of plastic working technology on the shielding performance of oyster shell was analyzed and the degree of dispersion within the polymer material was evaluated. In addition to powdered oyster shell, shielding sheets based on barium sulfate, tungsten, and bismuth oxide, were manufactured using the same process to compare their shielding performances. Thus, the relationship between plastic working and shielding performance was analyzed for radiation shields based on powdered oyster shell, and this relationship was evaluated against existing shielding sheets based on safer lead alternatives. 


\section{Methods}

Oysters were collected from the coasts of Nosan-ri, Gwangdo-myeon, and Tongyeong (South Korea). First, the meat was separated from the shells and then the shells (see Fig. 1) were washed with distilled water and dried for $12 \mathrm{~h}$ at $80{ }^{\circ} \mathrm{C}$ using a hot air dryer. Next, the dried shells were pulverized, with the particles sieved using a micromesh to ensure a uniform particle size. To perform plastic working, the refined oyster shell powder was subjected to heat treatment from $600{ }^{\circ} \mathrm{C}$ to $1,200{ }^{\circ} \mathrm{C}$ using muffle furnaces (Nabertherm, Co.; model: L5/11). Throughout this process, changes were observed in the morphology of the particles, and shielding sheets were manufactured by mixing the powdered oyster shell with a polymer.

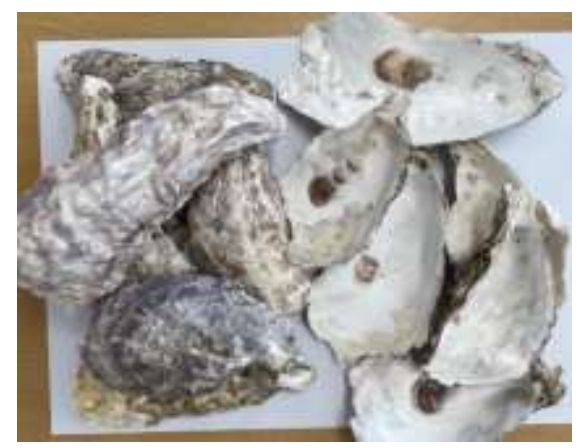

Figure 1. Oyster shells collected from the coasts of Nosan-ri, Gwangdo-myeon, and Tongyeong-si (South Korea).
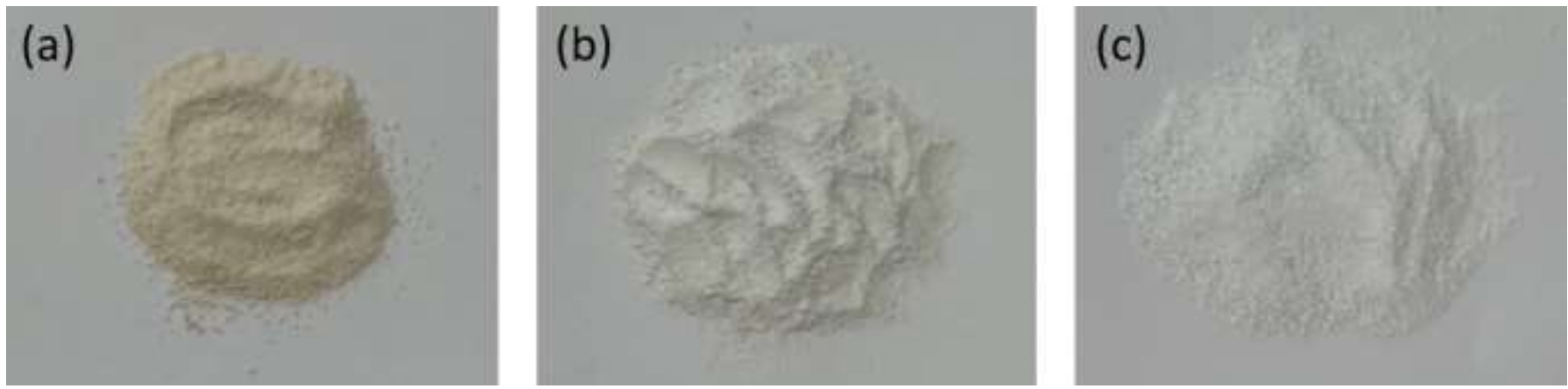

Figure 2. Oyster shell powder heat-treated using plastic working: (a) freshly pulverized powder without heat treatment; (b) powder after plastic working at $600{ }^{\circ} \mathrm{C}$; (c) powder after plastic working at $1,200{ }^{\circ} \mathrm{C}$.

Figure 2 shows photographs of refined oyster shell powder prior to plastic working and after plastic working at $600{ }^{\circ} \mathrm{C}$ and $1,200{ }^{\circ} \mathrm{C}$. To produce the radiation shielding sheet samples, high-density polyethylene (HDPE) was selected as the polymer material to be mixed with the powdered oyster shell and the base material. Owing to its excellent strength, HDPE is mainly used as a disposable plastic product ${ }^{25}$. The HDPE used in this study had a molecular weight of $\geq 4,000,000 \mathrm{~g} / \mathrm{mol}$ and a density of $0.91 \mathrm{~g} / \mathrm{cm}^{3}$.

To make the final composite materials, N-dimethylformamide (DMF, 99.5\%) was used to make a casting solution. Next, DMF ( $10 \mathrm{wt} \%)$ and powdered oyster shell $(70 \mathrm{wt} \%)$ were placed in a stirrer and stirred at $5000 \mathrm{rpm}$ to disperse the particles. Diisononyl phthalate (DINP, 0.85-0.95 wt\%) was used as a plasticizer to remove the voids inside the shielding sheet. To ensure the uniformity of the shielding performance of the final casting solution, contaminants were removed through filtering and defoaming, with the sheet finished using a compression molding calendar process. The final shielding sheets measured $300 \mathrm{~mm} \times 300 \mathrm{~mm} \times 0.3 \mathrm{~mm}$. The appearance of the manufactured shielding sheets is as shown in Fig. 3. This process was repeated to fabricate shielding sheets using barium sulfate, bismuth oxide, and tungsten to compare their respective shielding performances. Each of the manufactured shielding sheets had the same shielding material capacity and the same dimensions.

(a)

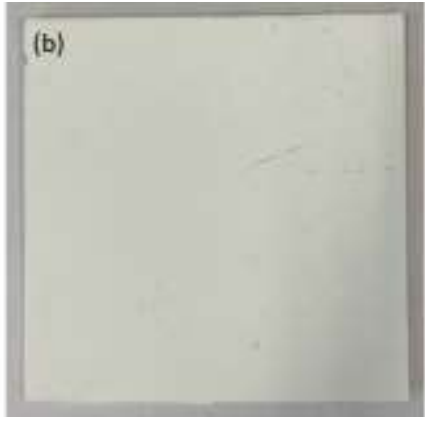

(c)

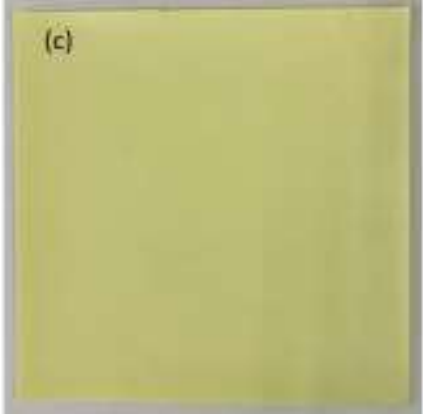

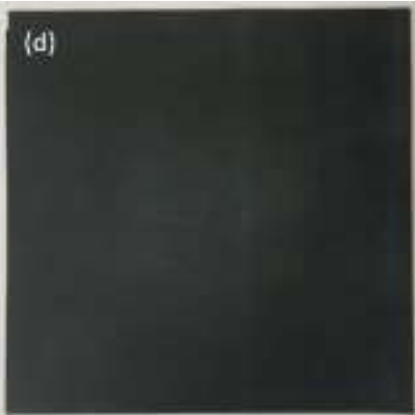

Figure 3. Contrasting appearances of shielding sheets manufactured by the same process: (a) powdered oyster shell $(1,200$ 
${ }^{\circ} \mathrm{C}$ ), (b) barium sulfate, (c) bismuth oxide, (d) tungsten.

The particle dispersibility of the shielding materials was observed using field-emission scanning electron microscopy (FESEM; S-4800, Hitachi) after thin-film sectioning using a microtome (RM2235, Leica).

Radiation transmission characteristics were used to evaluate the shielding performance of the sheets. When the radiation passing through a substance or medium interacts with the atoms or nuclei that make up the substance or medium, the intensity of the radiation is attenuated. In other words, when the thickness of the shielding sheet is considered as a shielded space, the thickness of the shielded sheet becomes a constant distance from which the shielding material and radiation react. The degree of reduction with respect to the radiation intensity per unit distance traveled in the shielding material is represented by the linear attenuation coefficient ${ }^{26}$ :

$$
\begin{gathered}
I=I_{0} e^{-\left(\mu_{1} x_{1}+\mu_{2} x_{2}\right)} \\
\mu_{1}=\frac{\left[\operatorname{In}\left(\frac{I_{0}}{I}\right)-\mu_{2} x_{2}\right]}{x_{1}},
\end{gathered}
$$

where $I$ and $I_{0}$ are the transmitted and incident radiation intensities, respectively; $\mu_{1}$ and $\mu_{2}$ are the linear attenuation coefficients of the shielding material and air, respectively; and $x_{1}$ and $x_{2}$ are the thickness of the shielding sheet and the distance from the radiation source to the shielding sheet, respectively.

The radiation intensity has a direct effect on the linear attenuation coefficient of the shielding material and the thickness of the shielding sheet. Therefore, if the thickness of the fabricated sheet is fixed, the relationship between the linear attenuation coefficient and the radiation intensity can be determined. Because the radiation intensity is inversely proportional to the shielding performance, the higher the intensity, the lower the shielding efficiency ${ }^{27}$. In this study, plastic working was used to reduce the inter-particle spacing and increase the number of interactions with incident radiation.

The shielding performance of the various shielding sheet samples was tested using the setup shown in Fig. 4. To express the radiation used in the experiment as effective energy, $\log _{e}$ is performed on both sides of the attenuation coefficient law $(I=$ $I_{0} e^{-\mu x}$ ), where $x$ is the attenuation thickness, and the slope of the graph of $y=-a x$ is used to measure the half-value layer. In addition, after obtaining the linear absorption coefficient, $\mu$, from this slope, the half-value layer was calculated as $0.693 / \mu^{28}$. For the effective energy calculation, Hubbell's mass absorption coefficient table was used to calculate the effective energy corresponding to the calculated half-value laye ${ }^{29}$. The shielding efficiency of the sheets was calculated as $(1-$ $\left.W / W_{0}\right) \times 100$, where $W$ and $W_{0}$ are the doses measured with and without a shielding sheet between the X-ray tube and the dosimeter, respectively ${ }^{30}$. The radiation was produced using an X-ray generator (Tosiba E7239, $150 \mathrm{kV}-500 \mathrm{~mA}, 1999$, Japan), and the dose detector was tested and calibrated using a DosiMax plus I (2019.iba Dosimetry. Corp, Germany).

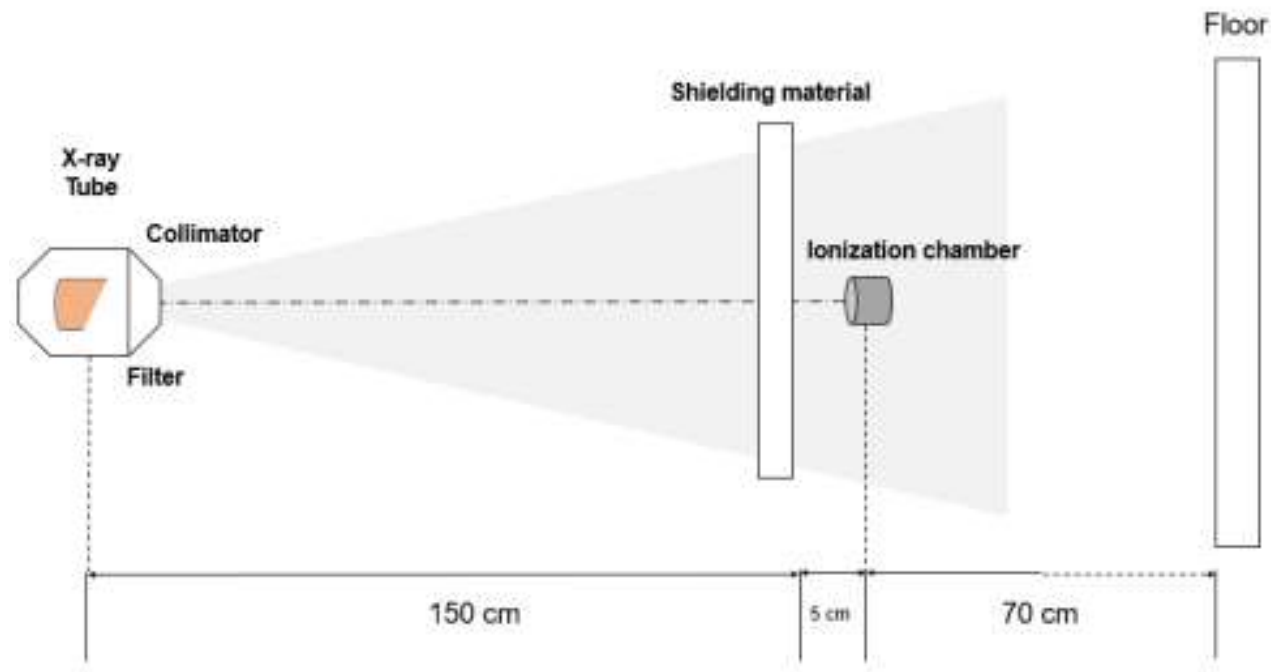

Figure 4. Experimental setup to evaluate the shielding performance of the shielding sheet materials. 


\section{Results}

Figure 5 shows the morphological changes in the oyster shell particle in response to being heated for plastic working. Compared to the untreated particles in Fig. 5(a), plastic working reduces the distance between the particles in Figs. 5(b) and (c), which correspond to temperatures of $600{ }^{\circ} \mathrm{C}$ and $1,200{ }^{\circ} \mathrm{C}$, respectively. The inter-particle spacing affects the density of the shielding material, thereby directly affecting its shielding performance ${ }^{31}$.
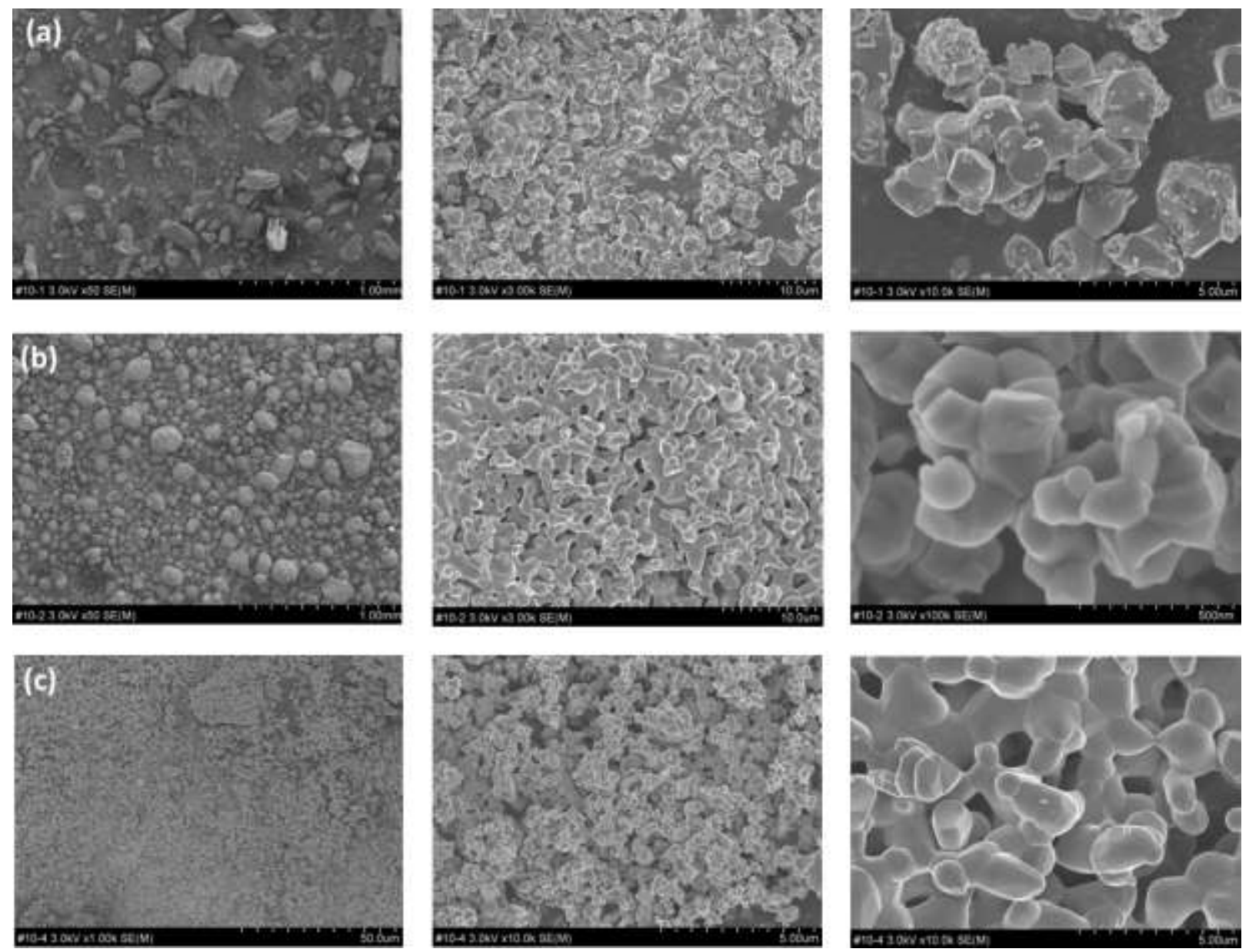

Figure 5. SEM images providing a comparative analysis of oyster shell particle morphology and spacing in response to plastic working: (a) untreated oyster shell particles, (b) particles after plastic working at $600{ }^{\circ} \mathrm{C}$, and (c) particles after plastic working at $1,200{ }^{\circ} \mathrm{C}$.

Table 1 lists the thicknesses, weights, and densities of the three oyster shell sample variations. Through plastic working, the particle size and the number of voids are both reduced, thus increasing the density of the sheet.

Table 1. Physical properties of the fabricated oyster shell-based shielding sheets.

\begin{tabular}{|c|c|c|c|}
\hline & Thickness $(\mathrm{mm})$ & Weight $(\mathrm{g})$ & Density $\left(\mathrm{g} / \mathrm{cm}^{3}\right)$ \\
\hline $\begin{array}{c}\text { Oyster shell sheet without } \\
\text { heat treatment }\end{array}$ & 0.32 & 23.39 & 8.12 \\
\hline $\begin{array}{c}\text { Oyster shell sheet with } \\
\text { plastic working at } 600{ }^{\circ} \mathrm{C}\end{array}$ & 0.31 & 28.12 & 10.07 \\
\hline $\begin{array}{c}\text { Oyster shell sheet with } \\
\text { plastic working at } 1,200^{\circ} \mathrm{C}\end{array}$ & 0.32 & 31.25 & 10.85 \\
\hline
\end{tabular}

In addition, the particle distribution within the oyster shell-based samples was analyzed by performing SEM imaging of sheet cross-sections (Fig. 6). It can be seen that the oyster shell powder processed at a high temperature has a high affinity with the HDPE, while the particles also appear widely dispersed. 

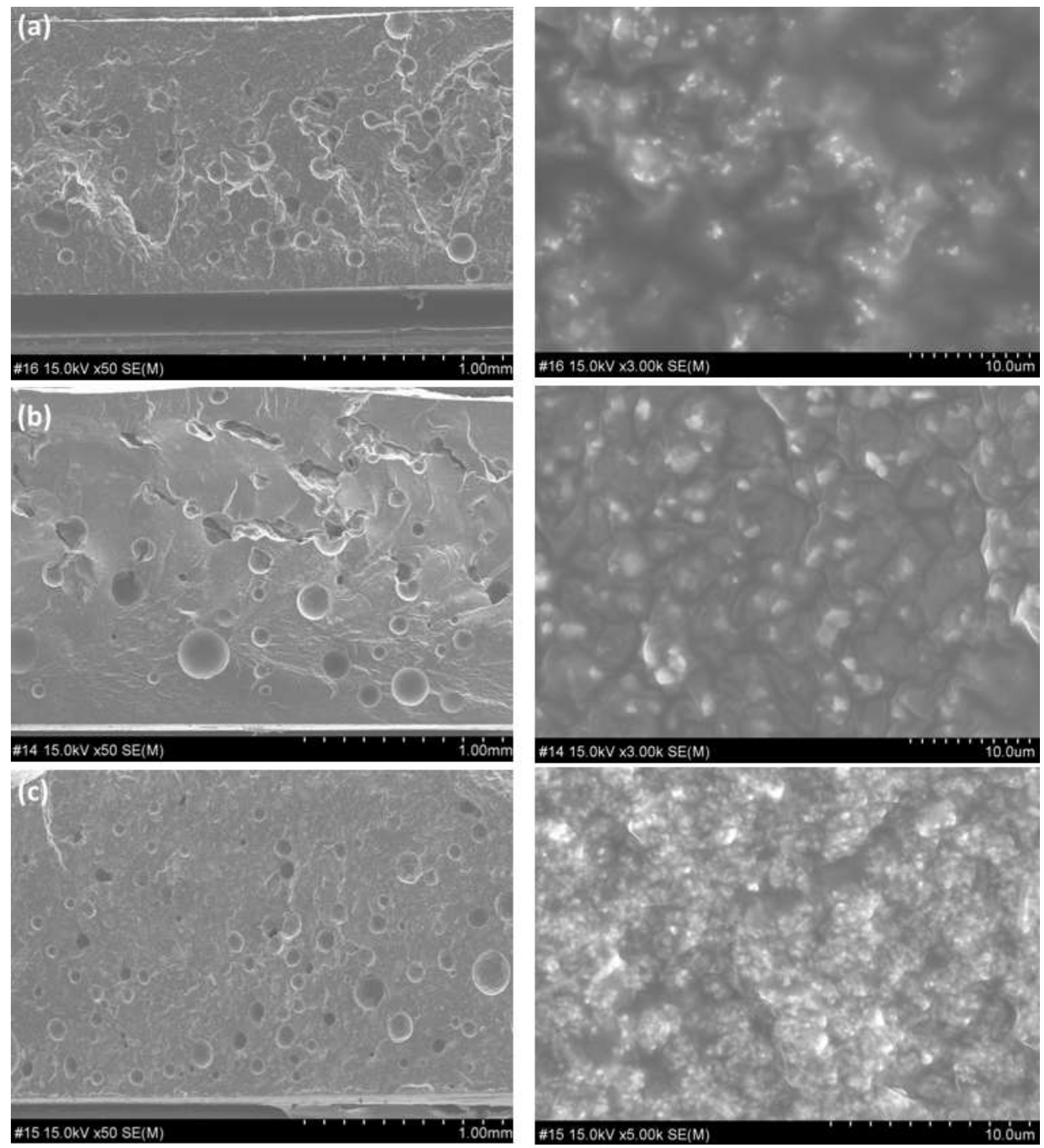

Figure 6. SEM images of sheet cross-sections providing a comparative analysis of the oyster shell particle morphology in the plastic working state: (a) untreated oyster shell particles, (b) particles after plastic working at $600{ }^{\circ} \mathrm{C}$, and (c) particles after plastic working at $1,200{ }^{\circ} \mathrm{C}$.

Table 2 summarizes the shielding performance experiment results for the oyster shell-based shielding sheets (alongside the data for a $0.3-\mathrm{mm}$-thick lead sheet). Similarly, Table 3 summarizes the shielding efficiencies of the sheets fabricated using existing lead alternatives (barium sulfate, bismuth oxide, and tungsten) and compares them to the performance of the oyster shell sheet fabricated by plastic working at $1,200{ }^{\circ} \mathrm{C}$.

The experimental data reveals that the oyster shell powder without plastic working provides a low shielding efficiency of approximately $18 \%$ in the low-energy X-ray region; however, this increases to approximately $37 \%$ for the sheet fabricated using plastic working at $1,200{ }^{\circ} \mathrm{C}$. As shown in Table 3, compared to barium sulfate, bismuth oxide, and tungsten sheets, which are more eco-friendly materials than lead, the shielding efficiency of the $1,200{ }^{\circ} \mathrm{C}$ plastic-worked oyster shell-based sheet is most similar to that of barium sulfate sheets (approximately 43\%). In addition, a lead sheet of equivalent of $0.3 \mathrm{~mm}$, which has the same thickness, is almost shielded, and it can be predicted that the oyster shell sheet has a shielding performance of about $40 \%$ of the lead performance. 
Table 2. Comparison of shielding performance for oyster shell-based shielding sheets fabricated with and without plastic working.

\begin{tabular}{|c|c|c|c|c|c|c|c|c|c|}
\hline \multirow{2}{*}{$\begin{array}{c}\text { Radiation } \\
\text { type }\end{array}$} & $\begin{array}{c}\text { Effective } \\
\text { X-ray } \\
\text { energy } \\
(\mathrm{keV})\end{array}$ & \multicolumn{6}{|c|}{ Mean exposure $(\mu \mathrm{R})$} & \multicolumn{3}{c|}{ Shielding rate $(\%)$} \\
\cline { 3 - 11 } & 24.6 & 106.90 & 0 & 87.72 & 84.47 & 67.01 & 17.94 & 20.98 & 37.32 \\
\hline \multirow{5}{*}{ X-ray } & 28.7 & 381.63 & 6.47 & 334.07 & 320.83 & 278.97 & 12.46 & 15.93 & 26.90 \\
\cline { 2 - 11 } & 32.5 & 799.70 & 48.87 & 738.57 & 702.13 & 630.80 & 7.64 & 12.20 & 21.12 \\
\cline { 2 - 11 } & 48.5 & 1318.33 & 144.83 & 1199.00 & 1180.67 & 1079.67 & 9.05 & 10.44 & 18.10 \\
\cline { 2 - 11 } & 54.9 & 1648.33 & 207.43 & 1510.33 & 1484.67 & 1372.67 & 8.37 & 9.93 & 16.72 \\
\hline
\end{tabular}

Table 3. Comparison of shielding performance for eco-friendly shielding sheets.

\begin{tabular}{|c|c|c|c|c|c|c|c|c|c|c|}
\hline \multirow[b]{2}{*}{$\begin{array}{c}\text { Radiation } \\
\text { type }\end{array}$} & \multirow{2}{*}{$\begin{array}{c}\text { Effective } \\
\text { X-ray } \\
\text { energy } \\
(\mathrm{keV})\end{array}$} & \multicolumn{5}{|c|}{ Mean exposure $(\mu \mathrm{R})$} & \multicolumn{4}{|c|}{ Shielding rate $(\%)$} \\
\hline & & Nothing & $\begin{array}{c}\text { Oyster } \\
\text { shell } \\
(1,200 \\
\left.{ }^{\circ} \mathrm{C}\right) \\
\end{array}$ & $\begin{array}{l}\text { Barium } \\
\text { sulfate }\end{array}$ & $\begin{array}{l}\text { Bismuth } \\
\text { oxide }\end{array}$ & Tungsten & $\begin{array}{l}\text { Oyster } \\
\text { shell }\end{array}$ & $\begin{array}{l}\text { Barium } \\
\text { sulfate }\end{array}$ & $\begin{array}{l}\text { Bismuth } \\
\text { oxide }\end{array}$ & Tungsten \\
\hline \multirow{5}{*}{ X-ray } & 24.6 & 106.90 & 67.01 & 61.04 & 41.69 & 19.23 & 37.32 & 42.90 & 61.00 & 82.01 \\
\hline & 28.7 & 381.63 & 278.97 & 236.51 & 160.15 & 114.36 & 26.90 & 38.03 & 58.04 & 70.03 \\
\hline & 32.5 & 799.70 & 630.80 & 550.80 & 463.81 & 351.76 & 21.12 & 31.12 & 42.00 & 56.01 \\
\hline & 48.5 & 1318.33 & 1079.67 & 1001.93 & 870.03 & 672.26 & 18.10 & 24.00 & 34.01 & 49.01 \\
\hline & 54.9 & 1648.33 & 1372.67 & 1318.66 & 1120.76 & 906.05 & 16.72 & 20.00 & 32.01 & 45.03 \\
\hline
\end{tabular}

\section{Discussion}

Although radiation-shielding equipment in medical institutions relies mainly on lead, owing to its toxicity, alternatives are urgently sought $32,33,34,35$. This study investigated the potential of powdered oyster shell as a new eco-friendly shielding material. The seafood industry generates a vast amount of waste in the form of discarded shells such as oyster shells, much of which goes to landfill. As such, the recycling of oyster shells is an important issue because of the environmental pollution caused by odors and leachate and the damage caused to the natural landscape ${ }^{36,37,38,39}$. Therefore, the radiation-shielding performance was evaluated with a view to broadening the scope of shellfish recycling. Table 4 summarizes the composition of several types of shellfish; furthermore, calcium carbonate accounts for the vast majority in each case. Oyster shells are the most abundant of the shells discarded by aquaculture and are easily accessible ${ }^{40,41}$. Moreover, there are cases where the radiation shielding efficiency of limestone has been studied ${ }^{42}$, and limestone also has calcium carbonate as its main component.

Table 4. Chemical compositions of different shellfish.

\begin{tabular}{|c|c|c|c|c|c|c|c|}
\hline \multirow{2}{*}{$\begin{array}{c}\text { Type of } \\
\text { shellfish }\end{array}$} & \multicolumn{7}{|c|}{ Elemental composition (\%) } \\
\cline { 2 - 8 } & $\mathrm{CaO}$ & $\mathrm{Na}_{2} \mathrm{O}$ & $\mathrm{CI} / \mathrm{MnO}$ & $\mathrm{SiO}_{2}$ & $\mathrm{SO}_{3}$ & $\mathrm{AI}_{2} \mathrm{O}_{3}$ & $\mathrm{Fe}_{2} \mathrm{O}_{3}$ \\
\hline Clams & 94.97 & 1.01 & - & 1.83 & 0.52 & 0.45 & 0.58 \\
\hline Cockles & 95.95 & - & - & 1.68 & 0.65 & 0.58 & 0.59 \\
\hline $\begin{array}{c}\text { Manila } \\
\text { clams }\end{array}$ & 92.79 & 1.13 & $0 / 0.13$ & 3.09 & 0.59 & 0.98 & 0.63 \\
\hline Oysters & 84.59 & 5.92 & $5.15 / 0$ & 1.63 & 1.19 & 0.45 & 0.32 \\
\hline
\end{tabular}


As the low density of calcium carbonate has a significant impact on its shielding effect, plastic working was investigated as a means of increasing its density and enhancing its radiation-attenuation capacity. This approach proved reasonably successful, with plastic working reducing the inter-particle distance by decreasing the distance from the center of the particles to their edges. Consequently, it is possible to increase the relative density by adding more particles within the same space. This approach improved the shielding performance, with the shielding efficiency of the oyster shell material produced using plastic working at $1,200{ }^{\circ} \mathrm{C}$ more than double that of the sheet fabricated without plastic working. During plastic working, calcium carbonate changes to calcium oxide in a certain temperature range; therefore, the characteristics of the heat-treated oyster shell powder sheet reflect those of calcium oxide.

With the exception of tungsten, none of the eco-friendly shielding materials considered in this study proved particularly effective when exposed to direct X-rays. This raises the possibility of creating tungsten/oyster shell powder hybrid shielding materials, which could strike a better balance in terms of weight and cost while providing high-level radiation protection. In addition, it should be noted that barium sulfate is considered adequate for shielding against the lower doses received from scattered rays, and the experimental results indicate that the shielding efficiency of the heated-treated oyster shell powder is similar to that of barium sulfate.

Another objective of this study was to investigate the impact on shielding performance as a result of using mixed materials. As a process technology, plastic working proved effective at increasing the density of the shielding sheet relative to one based on pure oyster shell powder, and could similarly benefit other materials. Nevertheless, further research is still needed to develop economical lightweight radiation shields. In addition, the development of technologies that can recycle waste materials, thereby enhancing the economic value of waste, should be considered an important objective that could have mutual benefits for improved shielding materials and sustainability.

\section{Conclusion}

This study evaluated the shielding performance of radiation-shielding sheets fabricated using oyster shell powder, with a 0.3mm-thick oyster shell shield exhibiting a shielding efficiency of $37.32 \%$ at an effective energy of $24.6 \mathrm{keV}$. This performance was facilitated by the development of a plastic working process to improve the shielding performance. This method increases the density of the shielding material by reducing the inter-particle spacing to enable tighter particle packing compared to pure oyster shell powder. Although the shielding efficiency of oyster shells alone is insufficient, it suggests the possibility of providing an excellent shield when mixed with other shielding materials. In addition, this study highlights the oftenoverlooked potential of waste materials and provides a valuable platform for further studies on the shielding performance of waste materials.

\section{References}

1. Mahadevappa, M. Radiation dose management for fluoroscopically guided interventional medical procedures. National Council on Radiation Protection and Measurements, Int. J. Med. Physiol. 21, 5789-5790 (2010). 10.1118/1.4747450

2. Kalra, M. K. et al. Strategies for CT radiation dose optimization. Radiology 230(3), 619-628 (2004). 10.1148/radiol.2303021726

3. Golding, S. J. \& Shrimpton, P. C. Commentary. Radiation dose in CT: Are we meeting the challenge?. Br. J. Radiol. 75(889), 1-4. 10.1259/bjr.75.889.750001,

4. Warren-Forward, H. et al. A comparison of dose savings of lead and lightweight aprons for shielding of 99 m-technetium radiation. Radiat. Prot. Dosim. 124(2), 89-96 (2007). 10.1093/rpd/ncm176

5. Zuguchi, M. et al. Usefulness of non-lead aprons in radiation protection for physicians performing interventional procedures. Radiat. Prot. Dosim. 131(4), 531-534 (2008). 10.1093/rpd/ncn244

6. Marichal, D. A. et al. Comparison of a Suspended Radiation Protection System versus Standard Lead Apron for Radiation Exposure of a Simulated interventionalist. J. Vasc. Interv. Radiol. 22(4), 437-442 (2011). 10.1016/j.jvir.2010.12.016

7. Livingstone, R. S., Varghese, A. \& Keshava, S. N. A study on the use of radiation-protective apron among interventionists in radiology. J. Clin. Imaging Sci. 8, 34 (2018). 10.4103/jcis.JCIS_34_18

8. Lu, H., Boyd, C. \& Dawson, J. Lightweight lead aprons: The emperor's new clothes in the angiography suite?. Eur. J. Endovasc. Surg. 57, 730-739 (2019). 10.1016/j.ejvs.2019.01.031

9. Kumar, S., Moro, L. N. \& Narayan, Y. Perceived physical stress at work and musculoskeletal discomfort in X-ray technologists. Ergonomics 47(2), 189-201 (2004). 10.1080/00140130310001617958 
10. Cai, Y., Hu, H., Lu, S. \& Jia, Q. Optimization of radiation shielding material aiming at compactness, lightweight, and low activation for a vehicle-mounted accelerator-driven DT neutron source. Appl. Radiat. Isot. 135, 147-154 (2018). 10.1016/j.apradiso.2018.01.021

11. Soylu, H. M., Yurt Lambrecht, F. Y. \& Ersöz, O. A. Gamma radiation shielding efficiency of a new leadfree composite material. J. Radioanal. Nucl. Chem. 305(2), 529-534 (2015). 10.1007/s10967-015-4051-3

12. Çetin, H., Yurt, A. Y. \& Yüksel, S. H. THE Absorption properties of lead-free garments for use in radiation protection. Radiat. Prot. Dosim. 173(4), 345-350 (2017). 10.1093/rpd/ncw004

13. Jamal AbuAlRoos, N., Azman, M. N., Baharul Amin, N. A. \& Zainon, R. Tungsten-based material as promising new lead-free gamma radiation shielding material in nuclear medicine. Phys. Med. 78, 48-57 (2020). 10.1016/j.ejmp.2020.08.017

14. Adlienè, D., Gilys, L. \& Griškonis, E. Development and characterization of new tungsten and tantalum containing composites for radiation shielding in medicine. Nuclear Instruments and Methods in Physics Research Section B: Beam Interactions with Materials and Atoms 467, 21-26 (2020). 10.1016/j.nimb.2020.01.027

15. Şakar, E., Özpolat, ÖF., Alım, B., Sayyed, M. I. \& Kurudirek, M. M. Phy-X/PSD: Development of a user friendly online software for calculation of parameters relevant to radiation shielding and dosimetry. Radiat. Phys. Chem. 166 (2020). 10.1016/j.radphyschem.2019.108496

16. $\mathrm{Li}, \mathrm{Q}$. et al. Enhanced radiation shielding with conformal light-weight nanoparticle-polymer composite. ACS Appl. Mater. Interfaces 10(41), 35510-35515 (2018). 10.1021/acsami.8b10600

17. Kim, H. M. et al. Recycling of seashell waste in concrete : A review. Constr. Build Mate 20, 751-764 (2018). 10.1016/j.conbuildmat.2017.12.009

18. Yao, Z. et al. Bivalve shell: Not an abundant useless waste but a functional and versatile biomaterial. Crit. Rev. Environ. Sci. Technol. 44(22), 2502-2530 (2014). 10.1080/10643389.2013.829763

19. Chung, C. W. Possibility to recycle domestic waste shells-with emphasis on oyster shells. Mag. Concr. Res. 11, 11-16 (2016). 10.14190/MRCR.2016.11.1.011

20. Owuamanam, S. \& Cree, D. Progress of bio-calcium carbonate waste Eggsehll and seashell fillers in polymer Composites: A review. Compos. Sci. Technol. 4, 70- (2020). 10.3390/jcs4020070

21. Elsheikh, N. A.A. Monte Carlo modelling of a neutron-induced gamma-ray sensor for landmine or explosive detection. J. Radiat. Res. Appl. Sci. 11(4), 403-407 (2018). 10.1016/j.jrras.2018.08.004

22. Chiou, I. J., Chen, C. H., \& Li, Y. H. Using oyster-shell foamed bricks to neutralize the acidity of recycled rainwater. Constr. Build Mate 64, 480-487 (2014). 10.1016/j.conbuildmat.2014.04.101

23. Seo, J. H., Park, S. M. Y., Yang, B. J. \& Jang, J. G. Calcined oyster shell powder as an expansive additive in cement mortar. Materials (Basel) 12(8), 1322- (2019). 10.3390/ma12081322

24. Chen, D., Zhang, P., Pan, T., Liao, Y. \& Zhao, H. Evaluation of the eco-friendly crushed waste oyster shell mortars containing supplementary cementitious materials. J. Cleaner Prod. 237, 1-33 (2019). 10.1016/j.jclepro.2019.117811

25. Rahman, T. \& Nurdiana, J. The effect of HDPE plastic fibres on concrete performance. Resour. Recycl. 5, 1-16 (2020). 10.20944/preprints202008.0413.v1

26. Kim, S. C. Development of air pressure mirroring particle dispersion method for producing high-density tungsten medical radiation shielding film. Sci. Rep. 11(1), 485 (2021). 10.1038/s41598-020-79819-5

27. Maghrabi, H. A., Vijayan, A., Mohaddes, F., Deb, P. W. \& Wang, L. Evaluation of X-ray radiation shielding performance of barium sulphate-coated fabrics. Fibers Polym. 17(12), 2047-2054 (2016). $10.1007 / \mathrm{s} 12221-016-5850-\mathrm{z}$

28. Kaur, T., Sharma, J. \& Singh, T. Experimental evaluation of gamma rays shielding parameters for $\mathrm{Zn}-\mathrm{Cd}-$ Sn-Pb quaternary alloy. Radiat. Phys. Chem. 156, 193-198 (2019). 10.1016/j.radphyschem.2018.11.010

29. Hubbell, J. H. Photon Mass Attenuation and Energy absorption Coefficients from $1 \mathrm{keV}$ to $20 \mathrm{MeV}$. Int. Appl. Radiat. Isot. 33, 1269-1290 (1982). 10.1016/0020-708X(82)90248-4

30. Pingale, P. L. Formulation, evaluation of fast dissolving tablet of anti-HIV drugs as fixed dose combination: 
Use of freeze-dried powder of Annona reticulata and comparison WITH synthetic superdisintegrants. J. Pharm. Sci. Innov. 8(1), 38-41 (2019). 10.7897/2277-4572.081124

31. Xie, T., Xu, K., Yang, B., \& He, Y. Effect of pore size and porosity distribution on radiation absorption and thermal performance of porous solar energy absorber. Sci. China (Technol. Sci.) 62, 2213-2225 (2019). 10.1007/s11431-018-9440-8

32. AbuAlRoos, N. J., Baharul Amin, N. A. \& Zainon, R. Conventional and new lead-free radiation shielding materials for radiation protection in nuclear medicine: A review. Radiat. Phys. Chem. 165 (2019). $\underline{10.1016 / j . r a d p h y s c h e m .2019 .108439}, \underline{108439}$

33. McCaffrey, J. P., Shen, H., Downton, B. \& Mainegra-Hing, E. Radiation attenuation by lead and nonlead materials used in radiation shielding garments. Med. Phys. 34(2), 530-537 (2007). 10.1118/1.2426404

34. Schlattl, H., Zankl, M., Eder, H. \& Hoeschen, C. Shielding properties of lead-free protective clothing and their impact on radiation doses. Med. Phys. 34(11), 4270-4280 (2007). 10.1118/1.2786861

35. Yue, K. et al. A new lead-free radiation shielding material for radiotherapy. Radiat. Prot. Dosim. 133, 256260 (2009). 10.1093/rpd/ncp053

36. Nam, G., Lee, N. J., \& Ahn, J. W. Sustainable management of oyster shell by-products and recent research techniques. J. Energ. Eng. 27, 1-11 (2018). 10.5855/ENERGY.2018.27.1.001

37. Kwon, H. et al. Recycling waste oyster shells for eutrophication control. Resour. Conserv. Recy. 41(1), 7582 (2004). 10.1016/j.resconrec.2003.08.005

38. Ramakrishna, C., Thenepalli, T., Han, C. \& Ahn, J. Synthesis of aragonite-precipitated calcium carbonate from oyster shell waste via a carbonation process and its applications. Korean J. Chem. Eng. 34(1), 225-230 (2017). 10.1007/s11814-016-0264-6

39. Lu, J. C., Li, X., Hao, Y., Wang, Y. C. Scalable recycling of oyster shells into high purity calcite powders by the mechanochemical and hydrothermal treatments. J. Cleaner Prod. 172, 1-8 (2017). 10.1016/J.JCLEPRO.2017.11.228

40. Jung. C. W. Possibility to Recycle Domestic Waste Shells -with Emphasis on Oyster Shells. Magazine of $R C R$. 11(1), 11-16 (2016). 10.14190/MRCR.2016.11.1.011

41. Silva, T. H., Mesquita-Guimarães, J., Henriques, B., Silva, F. S., Fredel, M. C. The potential use of oyster shell waste in new value-added by-product. Resources 8(1), 1-5 (2019). 10.3390/resources8010013

42. Sharaf, J. M. \& Saleh, H. Gamma-ray energy factor calculations and shielding effects of some Jordanian building structures. Radiat. Phys. Chem. 110, 87-95 (2015). 10.1016/j.radphyschem.2015.01.031 


\section{Acknowledgements (not compulsory)}

This work was supported by the Radiation Technology R\&D program of the National Research Foundation of Korea and funded by the Ministry of Science and ICT (grant no. 2020M2C8A1056950).

\section{Author contributions statement}

S.C. Kim designed the study, performed all data collection and analysis, wrote the main manuscript text, and prepared the figures.

\section{Competing interests}

The author declares no competing interests. 